\title{
La corne de l'abondance numérique
}

1 www.digital-grotesque.com (en anglais).

2 www.3d-shape.com (en allemand)

3 www.thingiverse.com (en anglais)

4 Eschbach A. Herr aller Dinge. Roman. Köln: Gustav Lübbe Verlag; 2011. Traduit en français sous le titre de «Maître de la matière», éd. Libraire L'Atalante, collection La Dentelle du Cygne, 2013.

erhard.taverna[at]saez.ch
Une machine magique, pouvant fabriquer n'importe quoi: du grès ressemblant au marbre, de n'importe quelle taille, résistant et artistique $(1,2)$, de la nourriture, des pièces de rechange pour les voitures et l'électroménager, des objets d'art, des jouets, voire un second réplicateur du même type. A en croire le président américain Barack Obama, chacun pourra tout simplement imprimer quasiment n'importe quel objet. Les marchés financiers ont réagi et depuis, des produits de placement sont apparus, misant sur le fait que l'impression tridimensionnelle est un produit d'avenir.

La technologie des imprimantes 3D connaît un développement vertigineux. Des appareils haut de gamme peuvent scanner n'importe quel objet et produire en petite série. Les métaux en poudre, les polymères et la céramique sont agencés couche après couche, après fusion au laser ou par électrons. La stéréolithographie permet de consolider, couche par couche, des structures en résine synthétique liquide ou en sable. Les prix ayant baissé, certains appareils sont aujourd'hui disponibles pour un usage domestique. Certains sites Web (3) fournissent des plans gratuits d'objets quotidiens. Ceux, qui ne souhaitent pas imprimer euxmêmes l'objet, peuvent télécharger le fichier CAD auprès d'un service en ligne et se faire livrer le produit.

Les applications médicales sont encouragées dans de nombreux laboratoires. Les premières applications en matériau inorganique sont déjà utilisées: pompe cardiaque en céramique, implants dentaires ou prothèses sur mesure. Les bioimprimantes sont censées fabriquer des tissus en fusionnant ligne par ligne des cellules ordinaires ou des cellules souches, injectées sous forme de gel liquide ou ancrées dans une structure collagène. Cette technique permet déjà de fabriquer de petits morceaux de peau, de cartilage ou d'os. Le tissu hépatique fabriqué à partir de vingt couches de cellules devrait faciliter la phase de test des médicaments, permettre de minuscules réparations des cellules cardiaques et aux tissus graisseux des implants après une lumpectomie. Un problème majeur du «Tissue Engineering» est l'irrigation sanguine, ce qui pourrait expliquer le fait que le développement de tissus cartilagineux est déjà très avancé, malgré la structure complexe des chondrocytes. Les premiers essais de valves cardiaques cultivées sont en cours. Elles conviendraient tout spécialement aux enfants, puisqu'elles se développent avec le cœur. Des vaisseaux sanguins complets fabriqués à partir de cellules du même organisme ont été utilisés avec succès comme pontages sur des animaux. Mais les organes

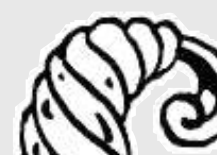
10 $\checkmark$ $1>$

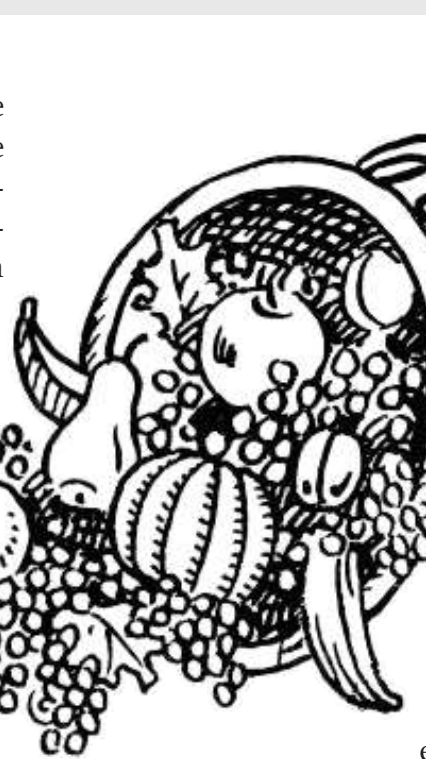
entiers sont encore loin de faire partie de la liste.

L'archéologie et la médecine légale travaillent avec des répliques exactes, des batteries fonctionnelles et des voitures en état de marche ont été conçues sur PC et matérialisées grâce à l'impression 3D. La société «Modern Meadow» aux Etats-Unis compte mettre sur le marché, d'ici 2050, les premiers hamburgers fabriqués artificiellement. A l'avenir, la population de la planète devrait pouvoir renoncer à abattre les animaux. Ces nouvelles procédures sont compatibles avec tous les processus de fabrication. Dans le design, l'art et l'architecture, elles font déjà presque partie de la routine. L'élimination des moules, du meulage, du forage et du fraisage permet d'économiser les matériaux. L'envoi de données d'impression au lieu de marchandises pourrait transformer radicalement la logistique. Il est même possible de fabriquer des armes de cette manière. Le cas de l'étudiant qui a fait circuler gratuitement sur le Web les plans d'un pistolet à imprimer en 3D a fait la une de tous les journaux du monde. Comme toujours, opportunités et risques sont à peine prévisibles et les commissions d'éthique, les législateurs et les instituts de pronostic sont rattrapés par l'évolution. Plus tard, tout le monde se targuera de l'avoir prévue.

Andreas Eschbach, écrivain de science-fiction, auteur du best-seller "Jésus vidéo», s’est penché de près sur ce développement. Dans son roman «Maître de la matière» [4], il décrit l'ascension et la chute d'un génie qui construit une machine magique pour chaque foyer, rendant obsolète l'ancien concept de propriété. Il imagine des nanomachines manipulant la matière au niveau de l'atome: «Elles peuvent changer radicalement le monde entier si on leur en donne l'ordre... ou le détruire, bien sûr.» D'après ce scénario, les imprimantes 3D annonceraient en quelque sorte la puissance d'un nouveau monde.

Erhard Taverna 